\title{
Child Maltreatment Within Military Families
}

\author{
Deborah A. Gibbs, MSPH, Sandra L. Martin, PhD, Monique Clinton-Sherrod, PhD, \\ Jennifer L. Hardison Walters, MSW, and Ruby E. Johnson, MS
}

Child maltreatment is a significant issue in the US military, with approximately 6,500 incidents (FY00-FY09 average) confirmed annually. Although rates of child maltreatment may be lower than in civilian populations, researchers have documented elevated levels of fatal child maltreatment and shaken baby syndrome in military communities. ${ }^{1}$ These indicators, and the unique characteristics and circumstances of military families, underscore the need for better understanding in this area.*

Within each service branch, Family Advocacy Programs are charged with preventing and responding to both child maltreatment and domestic violence. Commanders and service providers are required, and other personnel encouraged, to report known or suspected child maltreatment to the installation's designated point of contact. Cases are investigated, assessed, and reviewed by multidisciplinary committees whose members determine substantiation based on evidence and risk of further harm. Military service providers offer treatment and prevention services, often in collaboration with civilian child welfare agencies. This Research Brief summarizes research regarding risks for child maltreatment in military families and suggests a research agenda to inform prevention and intervention efforts.

\section{Protective and Risk Factors for Child Maltreatment}

Military life is rightly considered challenging. Several characteristics of military families, however, are likely to reduce risks of child maltreatment. These include low rates of illicit drug use, high proportions of two-parent families, and steady employment. In addition, service members are screened prior to entry for serious mental health problems and criminal histories.

\footnotetext{
* Complete citations for work described in this Brief can be found in the book
} chapter cited in reference 1 . Key terms are defined on page 3.

\section{Research Priorities}

- Gain an understanding of prevalence and patterns across all service branches

- Evaluate interventions for parents with co-occurring domestic violence or substance abuse

- Test strategies to engage at-risk parents in services

- Assess impact of repeated deployments

- Identify risk and resiliency factors following deployment

- Document experiences of families of National Guard and Reserve members

Factors that increase risk for child maltreatment include characteristics of both military families and military life. Military families are described as "young families with young children," with most children aged 7 or younger. Both alcohol abuse and domestic violence are more prevalent in military than civilian populations. ${ }^{2}$ Alcohol abuse is a strong correlate of domestic violence, which is in turn associated with child maltreatment.

Specific family stressors of military life include isolation from extended families and involuntary relocations. Service members also experience long work hours and lengthy absences from home for temporary assignments, peacekeeping missions, and combat deployments. As of 2009, an estimated 2 million children in US military families had been affected by deployments to Operation Enduring Freedom in Afghanistan and/or Operation Iraqi Freedom (OEF/OIF). 


\section{Domestic Violence and Child Maltreatment}

Domestic violence and child maltreatment are often found within the same families. Although estimates vary, $30 \%$ to $60 \%$ of families experiencing either child maltreatment or domestic violence also report the other form of violence. Children may be directly harmed during a domestic violence incident, or they may be maltreated by a domestic violence victim whose parenting capacity has been diminished as a result of abuse. Because exposure to parental violence has numerous shortand long-term impacts, it may constitute emotional abuse.

Research in Army families indicates that child maltreatment occurs twice as often in families with a history of domestic violence. Among married male soldiers who were child maltreatment offenders, one-quarter had also committed domestic violence on the same day. ${ }^{3}$ Domestic violence is in turn frequently associated with substance use, particularly alcohol abuse. Substance abuse was involved in one-quarter of domestic violence incidents committed by soldiers and associated with increased abuse severity. ${ }^{4}$

The presence of domestic violence complicates the determination of how best to protect the interests of children. Nonoffending parents may struggle to shield their children from the abusing spouse, and they may fear losing custody of their children if they are perceived to have failed to protect them. Protecting children is particularly challenging when the nonabusing parent is financially dependent on the abuser.

Fortunately, several aspects of military policies and services address these complexities. A single agency responds to both child maltreatment and domestic violence, with clinicians screening parents for substance abuse, although referrals are acknowledged to be less consistent than intended. Particularly when domestic violence is present, the military is likely to

\section{Protective and Risk Factors for Child Maltreatment}

Aspects of military life that may reduce risks:

- Low rates of illicit drug use among service members

- Two-parent families with at least one employed parent

- Barriers to persons with criminal histories or prior mental health issues

Aspects of military life that may increase risks:

- Isolation from extended families, frequent relocation

- Young parents with young children

- High rates of alcohol abuse and domestic violence

- Stresses associated with deployment remove offenders from the home, rather than maltreated children. ${ }^{5}$ Resources available to parents who are domestic violence victims include victim advocates, compensation if soldiers are separated from the military for reasons related to family violence, and the option of restricted reports that allow victims to access services without repercussions to offenders' military careers.

\section{Substance Abuse and Child Maltreatment}

Substance-abusing parents are two to three times more likely than other parents to maltreat their children. In the Army, $13 \%$ of soldiers who maltreated children were abusing alcohol or other drugs at the time. This is substantially lower than in civilian populations, likely because of low levels of illicit drug use in the military. Child maltreatment incidents involving substance abuse were more likely than others to involve neglect or emotional abuse and less likely to involve physical abuse. ${ }^{5}$

Higher levels of emotional abuse in child maltreatment incidents involving substance abuse suggest that many of these incidents involved parental violence. In fact, substance abuse was twice as common among child maltreatment offenders who committed domestic violence on the same day than among those who committed only child maltreatment.

\section{Deployment and Child Maltreatment}

Military deployments have been associated with increased stress for family members. Both nondeployed spouses and children may experience distress from disruption of family life and concern for the service member. Spouses have reported stress and depression that may hamper their ability to care for children during deployments; children have been found to have increased rates of depression, anxiety, and behavior problems.

The association of deployment with both parental and child distress during deployments, particularly combat deployments, raises concern regarding risk of child maltreatment at these times. In fact, both military and civilian agencies have documented increases in substantiated child maltreatment during large-scale OEF/OIF deployments. An in-depth examination of all incidents of child maltreatment among Army families between 2001 and 2004 found higher rates during times of soldiers' deployment than at other times. ${ }^{6}$ The rate of substantiated child maltreatment by female civilian parents was more than three times greater during deployments; the rate of neglect was nearly four times higher. Increases occurred regardless of parent demographics, child ages, or soldier rank. 
These findings underscore the need for additional supportive and preventive services for military families during deployments. Resources offered on installations often include respite child care and support groups. Participation in these services is voluntary, however, and parents experiencing distress may not take advantage of them. Army medical providers who treat civilian spouses are instructed to inquire about deployments, assess civilian parents' well-being, and make appropriate referrals.

\section{Future Outlook and Research Needs}

Opportunities for future research lie in better understanding which families are at risk and strengthening prevention and treatment services. Describing child maltreatment incidence and patterns across the entire military is a crucial first step, because most existing research is based on Army families and may not reflect the characteristics of other service branches.

Research can also inform the military's response to parents engaged in or at risk of domestic violence, particularly when the domestic violence is alcohol-fueled. Further analyses are needed to disentangle the complex relationships among child maltreatment, domestic violence, and substance abuse. Effectiveness evaluations are needed for interventions that address substance abuse and domestic violence separately and for those that address both issues, such as Behavioral Couples Therapy. ${ }^{7}$ Finally, strategies to engage and retain military couples in available prevention and intervention services should be evaluated, particularly for civilian spouses, who cannot be required to participate in services. Parenting outcomes are an important focus for such studies.

Several aspects of OEF/OIF deployments suggest priorities for research. First, these operations have been characterized by lengthy deployments with truncated intervals between deployments. This underscores the need to examine family well-being across repeated deployments and evaluate support services for both parents and children. Second, increased casualty survival rates mean that many service members-and their families-must deal with physical injuries, cognitive changes, and mental health issues that may affect service members' functioning. Researchers therefore need to assess the impacts of deployment experiences on family violence during the months and years following service members' return from deployments. Finally, better information is needed about the experiences of families of National Guard and Reserve members; they have experienced unprecedented levels of deployment during OEF/OIF but often lack access to support services available to active duty families.
The military is unique among employers in its allencompassing involvement in the lives of service members, which is reflected in its increasing attention to family welfare. Better understanding of child maltreatment in the military can inform prevention and support efforts, with immediate and long-term benefits for children, families, and service members themselves.

\section{Definitions}

Child maltreatment: neglect or physical, sexual, or emotional abuse by a parent or caretaker under circumstances indicating that the child's welfare is harmed or threatened.

Domestic violence: assault, battery, threat to injure or kill, other act of force or violence, or emotional maltreatment inflicted on a partner. The military has traditionally focused on spousal abuse but increasingly responds to abuse between unmarried intimate partners.

Family Advocacy Program (FAP): within each service branch, the program responsible for the prevention, identification, evaluation, treatment, rehabilitation, follow-up, and reporting of family violence.

Service member: a member of any service branch, including the Army, Navy, Air Force, Marine Corps, and Coast Guard. Unless specified, all references are to active duty service members rather than members of the National Guard and Reserve.

Soldier: a member of the US Army.

Substantiation: determination that the preponderance of available information indicates that abuse has occurred.

\section{References}

1. Gibbs DA, Martin SL, Clinton-Sherrod M, Hardison Walters JL, Johnson RE. Child maltreatment within military families. In: Wadsworth SM, Riggs D, editors. Risk and resilience in US military families. New York: Springer Science+Business Media; 2010. This chapter contains complete citations for work described in this Brief.

2. Bray RM, Marsden ME. Trends in substance use among US military personnel: the impact of changing demographic composition. Subst Use Misuse. 2000;35(6):949-69.

3. Martin SL, Gibbs DA, Johnson RE, Rentz ED, Clinton-Sherrod M, Walters JL, Sullivan K. Male soldier family violence offenders: spouse and child offenders compared to child offenders. Violence Vict. 2009;24(4):458-68. 


\section{Child Maltreatment Within Military Families}

4. Martin SM, Gibbs, DA, Johnson RE, Sullivan K, Clinton-Sherrod M, Hardison Walters JL, Rentz ED. Substance use by soldiers who abuse their spouses. Violence Against Women, 2010;16(11):1295-310.

5. Gibbs DA, Martin SL, Johnson RE, Rentz ED, Clinton-Sherrod M, Hardison J. Child maltreatment and substance use among US Army soldiers. Child Maltreat. 2008 Aug;13(3):259-68.

6. Gibbs DA, Martin SL, Kupper LL, Johnson RE. Child maltreatment in enlisted soldiers' families during combat-related deployments. JAMA. 2007;298(5):528-35.

7. Fals-Stewart W, Kennedy C. Addressing intimate partner violence in substance-abuse treatment. J Subst Abuse Treat. 2005;29(1):5-17.

\section{About the Authors}

Deborah A. Gibbs, MSPH, is a senior policy analyst and deputy director of the Women, Children, and Families Program at RTI International.

Sandra L. Martin, PhD, is the associate dean for research in the Gillings School of Global Public Health and professor and associate chair for research within the Department of Maternal and Child Health at the University of North Carolina at Chapel Hill.

Monique Clinton-Sherrod, PhD, is a research psychologist and research program area leader for Substance Use and Violence in RTI International's Risk Behavior and Family Research Program.

Jennifer L. Hardison Walters, MSW, is a research analyst in RTI's Crime, Violence, and Justice Program.

Ruby E. Johnson, MS, is a research statistician with RTI International.

RTI Press Research Briefs and Policy Briefs are scholarly essays on policy, methods, or other topics relevant to RTI areas of research or technical focus.

RTI International, 3040 Cornwallis Road, PO Box 12194, Research Triangle Park, NC 27709-2194 USA

Tel: 919.541.6000Ｆax:919.541.5985Ｅ-mail: rtipress@rti.org

Web site: www.rti.org

O2011 Research Triangle Institute. RTI International is a trade name of Research Triangle Institute.

All rights reserved. Please note that this document is copyrighted and credit must be provided to the authors and source of the document when you quote from it. You must not sell the document or make a profit from reproducing it.

RTI Press publication RB-0002-1105

doi:10.3768/rtipress.2011.rb.0002.1105

www.rti.org/rtipress 